\title{
A caminho de uma filosofia sem alma. Uma abordagem psicofísica sobre a crítica da subjectividade de Nietzsche
}

\author{
Pietro Gori**
}

Resumo: A crítica à noção do Eu é um tema do pensamento de Nietzsche que pode ser contextualizado dentro do debate oitocentista sobre a psicologia científica. Esse debate encontra em autores como Friedrich Lange e Ernst Mach dois pontos de referência importantes. Ambos perspectivam um desenvolvimento das ciências cognitivas em direcção a uma "psicologia sem alma" favorecendo assim um afastamento desta disciplina da velha metafísica da substância. No presente artigo nos referiremos aos autores encimados para compreender se e em que sentido Nietzsche pensa na necessidade de uma rejeição da noção de sujeito em filosofia.

Palavras-chave: psicologia - psicofísica - Lange - Mach.

\footnotetext{
* Tradução de Antonio Cardiello.

** Pesquisador do IFLNOVA - FCSH, da Universidade Nova de Lisboa, Lisboa, Portugal.

Endereço eletrônico: pietro.gori@gmail.com
} 
Gori, P.

\section{Introdução}

Na sua fase de produção mais tardia, Nietzsche explora, com particular atenção, o problema do sujeito (ou Eu), já que esse constitui um dos elementos distintivos da visão do mundo ocidental e da metafísica da substância sobre a qual ela assenta. Entre as reflexões mais significativas de Nietzsche em torno deste tema, destacam-se aquelas incluídas na primeira seção de Além do Bem e do Mal, retomadas sucessivamente no capítulo de Crepúsculo dos Ídolos dedicado à "Razão" na filosofia. Nessa obra de 1888, Nietzsche acusa a linguagem de ter aberto caminho a um "fetichismo grosseiro". "Esse feticismo - escreve Nietzsche - vê em todo o lado agentes e ações (...) acredita no 'Eu', no Eu como ser, no eu como substância, e projeta a crença no Eu-substância de todas as coisas (...) O ser é acrescentado como causa do pensamento, incluído às escondidas" (GD/ CI, A razão na filosofia, 5, KSA 6.77). Aqui a posição de Nietzsche opõe-se claramente a um pensamento filosófico ainda subordinado a uma concepção acrítica do $\mathrm{Eu}$, ao mesmo tempo incapaz de rejeitar o pensamento comum. Assim, Nietzsche, em $J G B / B M$ 16, mina a legitimidade da proposição "eu penso" enquanto certeza imediata. ${ }^{1}$ Antes de falar disso, avisa Nietzsche, seria preciso solucionar uma série de questões mais complexas:

por exemplo, que sou eu quem pensa, que é absolutamente necessário que algo pense, que o pensamento é o resultado da atividade de um ser concebido como causa, que exista um "eu"; enfim, que se estabeleceu de antemão o que se deve entender por pensar e que eu sei o que significa pensar (JGB/BM 16, KSA 5.29).

1 Acerca da crítica nietzschiana e kantiana do "eu penso" de Descartes veja-se, por exemplo, Bornedal (2010) e Loukidelis (2005).

14 Cad. Nietzsche, Guarulhos/Porto Seguro, v.38, n.2, p. 13-35, maio/agosto, 2017. 
A caminho de uma filosofia sem alma. Uma abordagem psicofísica ...

Uma vez subdividida a proposição nas duas partes que a compõem, ${ }^{2}$ ocorre assinalar que a noção de Eu descende de uma consideração não-filosófica de ambas, e carrega consigo os vestígios de uma metafísica ingênua. A conclusão de Nietzsche é que:

Em lugar dessa segurança em que o vulgo talvez venha a crer, o filósofo por seu lado não retira mais que um punhado de problemas metafísicos, de verdadeiros casos de consciência intelectuais que podem ser colocados da seguinte forma: De onde retiro minha noção de "pensar"? Por que devo crer na causa e no efeito? Com que direito posso falar de um "eu" e de um "eu" como causa e para cúmulo, causa do pensamento? (JGB/BM 16, KSA 5.29)

A ordem dos problemas apresentada por Nietzsche é clara, mas isso não torna as questões por resolver menos problemáticas, sobretudo se considerarmos o papel fundamental - em Nietzsche que a noção de Eu assume na representação comum e imediata dos atos dos pensamentos e o seu consequente estatuto de referência imprescindível pela acção individual (prática e moral). O quadro assume uma complexidade maior quando o discurso sobre o Eu toca a noção de alma, e se passa de um problema clássico da tradição filosófica e psicológica a questões inerentes à religião em geral e ao cristianismo em particular. Nietzsche torna explícita esta ligação em JGB/BM 54, quando volta à questão do sujeito para reiterar que a perspectiva aceite desde a época de Descartes era de atribuir ao pensamento uma causa, ao passo que a filosofia moderna teria a capacidade de ultrapassar tal concepção. Essa, de fato, mediante uma crítica aos conceitos de sujeito e predicado, atuaria

2 No que respeita o dualismo entre $o$ ato do pensamento e o seu alegado sujeito, Nietzsche dedica uma atenção particular, especialmente nos anos posteriores a Além do Bem e do Mal. Veja-se, sobretudo, GM/GM, I, 13, KSA 5.278 e a sua nota preparatória Nachlass/FP 1886, 7 [1], KSA 12.247. Cf ainda GD/CI, Os quatro grandes erros, 3, KSA 6.90, que retoma e unifica as observações desenvolvidas em Além do Bem e do Mal e Genealogia da Moral. Em torno da relação problemática entre agente e ação, veja-se Pippin (2010, capítulo 4).

Cad. Nietzsche, Guarulhos/Porto Seguro, v.38, n.2, p. 13-35, maio/agosto, 2017. | 15 
Gori, P.

um atentado contra a suposição fundamental da doutrina cristã. A filosofia moderna sendo uma crítica do conhecimento teórico é secreta ou abertamente anti-cristã (...). Uma certa feita acreditava-se na "alma" como na gramática e no sujeito gramatical: afirmava-se "eu" é a condição, "penso" é o predicado e o condicionado, o pensar é uma atividade para a qual é preciso imaginar um sujeito como causa. Depois se tentou, com tenacidade e astúcia admiráveis, sair desta rede - acreditou-se então que o oposto era verdadeiro, "penso" condição, "eu" condicionado; sendo o "eu" portanto nada mais que uma síntese produzida pelo pensar por si mesmo. (JGB/BM 54, KSA 5.73)

As observações de Nietzsche referem-se, com toda probabilidade, a um debate ocorrido na segunda metade do século XIX, que incluiu Friedrich A. Lange (autor, como é sabido, muito estudado por Nietzsche). ${ }^{3} \mathrm{O}$ Eu de que Nietzsche fala em $J G B / B M$ não é, na verdade, diferente do conceito de alma presente nas páginas de História do materialismo de Lange ou da definição que lhe deu Ernst Mach no mesmo período, isto é, a alegada "unidade psíquica" que a ciência procura encontrar no interior do cérebro (MACH, 1902, p. 21). ${ }^{4}$ Mach, em particular, sublinha a dependência do saber filosófico e científico de uma tradição religiosa de pensamento e lamenta o fato de a ciência insistir na busca de um "lugar da alma" entre os gânglios do cérebro, sem considerar a hipótese de um princípio substancialístico desse tipo possa até não existir. $\mathrm{O}$ problema de fundo que Mach detecta é o da relação entre "corpo e Eu (matéria e alma)", ou, mais em geral, entre os dois âmbitos do físico e do psíquico, uma questão largamente debatida durante o século XIX e que encontrou na psicofísica de Gustav Fechner um dos principais pontos de referência. As pesquisas de Mach baseiam-se precisamente

3 A influência de Lange sobre o pensamento de Nietzsche foi amplamente demonstrado em Stack (1983) e Salaquarda (1978), e sucessivamente confirmado por outros estudos no âmbito da Quellen-Forschung.

40 discurso já aparece na primeira edição da obra de Mach, publicada em 1886 e adquirida por Nietzsche provavelmente no mesmo ano (Beiträge zur Analyse der Empfindungen, p. 19, n. 13).

16 Cad. Nietzsche, Guarulhos/Porto Seguro, v.38, n.2, p. 13-35, maio/agosto, 2017. 
A caminho de uma filosofia sem alma. Uma abordagem psicofísica ...

nos resultados de Fechner, desenvolvendo-os em direcção a um monismo neutral que solucionasse, em termos antimetafísicos, a relação entre físico e psíquico. ${ }^{5}$ Também Lange aproximou-se de Fechner quando começou a investigar os limites dos estudos sobre a relação corpo-mente propostos pelo materialismo e pela fisiologia dos órgãos de sentido, adotados no âmbito psicológico, quando a psicologia procurava um fundamento substancialístico do seu principal objeto de estudo, e quando, mesmo por isso, ainda não tinha saído de um estádio "pré-científico" de análises. Não surpreende, portanto, que tanto Lange como Mach, na senda de Franz Brentano, tenham perspectivado a admissibilidade dessa posição sem o risco de cair em formulações paradoxais. $\mathrm{O}$ argumento do debate oitocentista relativo ao problema do sujeito pode ser adoptado para enfrentar a questão do Eu que Nietzsche expõe em JGB/BM. Antes de mais, é possível extrair desse debate alguns elementos que contextualizam a "questão da metafísica" reportada por Nietzsche em JGB/BM 16 (ou seja, se é possível falar de um Eu como causa dos pensamentos, e a partir de que pressupostos); em segundo lugar, o debate pode ajudar a compreender em que sentido Nietzsche sugere a rejeição da noção de sujeito por parte do pensamento filosófico e, por conseguinte, direciona o seu caminho para uma "filosofia sem Eu".

\section{A abordagem psicofísica: de Fechner a Mach}

As pesquisas psicológicas desenvolvidas na Alemanha, na segunda metade do século XIX, são caracterizadas principalmente por uma intenção de tornar a psicologia numa ciência autêntica, isto é, uma disciplina idônea para fornecer instrumentos de medida do próprio objeto de investigação. $O$ problema da fundação da psicologia

50 nome "monismo neutral" foi utilizado pela primeira vez por Bertand Russel, para indicar a orientação, comum a um grande número de filósofos e cientistas do início do século XX, que acabaria por ser inaugurado precisamente por Mach ( $c f$. BANKS, 2003, p. 136).

Cad. Nietzsche, Guarulhos/Porto Seguro, v.38, n.2, p. 13-35, maio/agosto, 2017. $\mid 17$ 
Gori, P.

científica surgira havia algum tempo, reunindo as reflexões que Kant tinha elaborado na Crítica da razão pura relativamente à questão da psicologia do conhecimento da alma como substância, e ao problema filosófico inerente da "parecença da alma com o corpo orgânico" (KANT, 1974, A384, A392-393 e B427). ${ }^{6}$ A tentativa dos autores ativos na primeira metade do século XIX de solucionar, ou, pelo menos, contornar as dificuldades denunciadas por Kant, originou múltiplas soluções. Entre elas, as mais eficazes e significativas foram aquelas atribuíveis a Johannes Müller, Johann F. Herbart e Gustav Fechner. ${ }^{7} \mathrm{O}$ contributo destes especialistas constituiu o ponto de referência para as investigações posteriores, que foram caracterizadas pela recusa dos princípios metafísicos que ainda qualificaram os estudos psicológicos em prol de um mais honesto "regresso a Kant".

Não me é possível, neste artigo, aprofundar os vários aspectos dessa questão. ${ }^{9}$ Limitar-me-ei apenas - e muito rapidamente - à proposta de Fecnher, sendo este a referência principal quer de Lange quer de Mach. Fechner é conhecido por ter fundado uma nova disciplina, a psicofísica, definida por ele como "a doutrina exata das relações funcionais ou de dependência entre corpo e alma [Körper und Seele]; mais em geral entre mundo corpóreo e espiritual, físico e psíquico" (FECHNER, 1860, v. 1, p. 8). A psicofísica aspira à compreensão destas relações e subjaz a uma interpretação peculiar da relação corpo-mente. Fechner não organiza a sua pesquisa segundo a perspectiva tradicional, considerando físico e psíquico como duas entidades distintas entre elas. Pelo contrário, ele promove uma ontologia de matriz espinosista e considera o mundo corpóreo e o espiritual como dois aspectos da mesma realidade, desprovidos

6 Quanto à posição de Kant relativa à possibilidade de enfrentarmos um "problema psicofísico", veja-se Martinelli (1999, p. 9-19).

7 Sobre Herbart e Fechner vejam-se em particular Banks (2003, cap. 3 e 6), Heidelberger (1996), Sachs-Hombach (1993) e Leary (1980).

8 Em relação a isto, vejam-se Poggi (1977), Martinelli (1999) e Lehmann (1987).

9 Para um estúdo aprofundado do tema, veja-se Guzzardi (2010).

18 | Cad. Nietzsche, Guarulhos/Porto Seguro, v.38, n.2, p. 13-35, maio/agosto, 2017. 
A caminho de uma filosofia sem alma. Uma abordagem psicofísica ...

de qualquer distinção de carácter metafísico. Esta visão monística representa um passo adiante nos estudos da psicologia em comparação com a metafísica escolástica adotada anteriormente. Fechner, de facto, se afasta da ideia de que a alma seja uma substância dotada de uma autonomia ontológica no que diz respeito ao corpo, e assim invalida qualquer tentativa de determinar a sede dessa alegada entidade espiritual no cérebro ou em qualquer outra parte do organismo. Contudo, a psicofísica fica marcada por um fundamento metafísico, representado pelo modo como é definida a unidade substancial que relaciona o físico e o psíquico. A matriz espinozista (ou schellinghiana) da teoria de Fechner impede, então, que o seu sistema se erga como modelo de uma "ciência da alma", visto que continua presente um elemento irresolúvel, cuja natureza não pode ser investigada, e que, por isso, não pode ser descrito ou quantificado.

Sobre este aspecto foca-se a crítica de Mach, que em Análise das sensações propõe uma possível solução para definir a relação entre físico e psíquico sem tropeçar nas dificuldades levantadas pela psicofísica, aceitando a estrutura monística dela. A proposta de Mach é conhecida pelo nome de monismo neutral e consiste em admitir os "elementos" (ou "sensações") como única realidade. Esses elementos são, por exemplo, cores, sons, temperaturas, pressões ou, como diria Mach (1902, p. 4), "As componentes últimas [da realidade investigada cientificamente] que até agora não foi possível subdividir ulteriormente". Os elementos de que fala Mach não possuem nenhuma característica por si só; podem ser descritos tanto em termos físicos como em termos psíquicos, consoante a dimensão tomada como referência durante a análise (quer uma dimensão constituída por objectos físicos exteriores a nós - Körper - ou do nosso corpo - Leib). ${ }^{10}$

10 Mach também acrescenta que, na relação específica com a corporeidade individual, os elementos são descritos como sensações e, tendo em conta - ainda segundo Mach - que não é possível estabelecer uma relação com elas fora do nosso corpo, para a maioria dos casos os termos "sensações" e "elementos" funcionam como sinônimos. Esta equiparação gerou várias incomprensões ao longo dos anos. Para uma análise aprofundada a respeito dos temas dos elementos em Mach, veja-se ainda Banks (2003).

Cad. Nietzsche, Guarulhos/Porto Seguro, v.38, n.2, p. 13-35, maio/agosto, 2017. 
Gori, P.

Pode-se reparar logo que a definição de Mach evita a dificuldade metafísica na qual cai a psicofísica, tornando os elementos um substrato não determinável e, sobretudo, não definitivo. São estes os elementos que um investigador pode adotar para descrever os fenômenos estudados utilizando uma abordagem metodológica, sem a necessidade de lhes atribuir um estatuto ontológico. Mach, ao formular o seu "princípio do paralelismo completo entre psíquico e físico", assume uma posição superior àquela de Fechner, num sentido explicitamente antimetafisico. Corroborado pela sua concepção dos elementos, Mach de fato declara que a perspectiva por ele defendida

diferencia-se daquela de Fechner, que considerava os fenômenos físicos e psíquicos dois aspectos diferentes de uma única realidade. Em primeiro lugar, a nossa concepção não tem, de maneira nenhuma, um substrato metafísico, pois corresponde apenas a uma expressão generalizada de experiencias. Para além disso, nós não distinguimos dois aspectos diferentes de uma terceira entidade incógnita; os elementos que encontramos na experiência, dos quais investigamos a ligação, são sempre os mesmos, de $u m$ só tipo e apenas em consequência das relações que têm entre si, se apresentam ou como elementos físicos ou como elementos psíquicos. (MACH, 1902, p. 49-50)

Relativamente à psicofísica de Fechner, Mach rejeita o fundamento metafísico, mas aceita a ideia da superação da distinção entre mundo corpóreo e mundo espiritual, insistindo, também ele, na dimensão funcional da relação entre estes dois âmbitos. Já que não há fenômenos físicos ou psíquicos, mas apenas uma interpretação física ou psíquica dos mesmos eventos, no que concerne a dimensão da pesquisa científica só é possível considerar a maneira como os elementos se apresentam agregados. Focando as relações relativamente mais estáveis, é possível definir "os conceitos substancialísticos de 'corpo' e 'alma' (matéria e alma)" (MACH, 1902, p. 4), os quais, evidentemente, no sistema de Mach perdem todos os valores de subsistência independente com respeito aos elementos que os compõem.

$20 \mid$ Cad. Nietzsche, Guarulhos/Porto Seguro, v.38, n.2, p. 13-35, maio/agosto, 2017. 
A caminho de uma filosofia sem alma. Uma abordagem psicofísica ...

\section{O Eu como "unidade ideal"}

As observações de Mach em torno da questão do Eu inseremse no contexto encimado. Antes de mais, Mach define a unidade psíquica como um conjunto de sensações que remetem para uma dimensão corpórea individual [Leib], e por isso subtrai ao Eu qualquer determinação que prescinde dessa relação:

O conjunto de lembranças, humores, sentimentos, ligados a um determinado corpo designado de "Eu" se apresenta como relativamente persistente. Eu posso ocupar-me disto ou daquilo, posso estar sossegado e alegre ou irritado de mal-humorado. Permanece todavia (...) uma suma de elementos persistentes que permitem reconhecer a identidade do Eu. Por outro lado, também o Eu tem uma persistência apenas relativa. A aparente persistência do Eu consiste sobretudo na continuidade, na lentidão da mudança. (MACH, 1902, p. 2-3)

Segundo essa perspectiva, o Eu tem uma origem puramente lógico-prática: é de fato a necessidade de orientação que permite ao nosso intelecto construir uma referência unitária a partir de um conjunto de sensações. Essa referência ajuda a acompanhar as mutações de uma pessoa admitindo a identidade. Fora desse processo, não existe nada. Mach nega qualquer valor essencial ao Eu e aos corpos [Körper]: ambos são para ele simples construções do pensamento, "meios alternativos para uma orientação provisória que servem apenas para determinados fins práticos" (MACH, 1902, p. 10). O Eu, em particular, é designado por Mach "unidade ideal", cuja função é a de reunir "todos os elementos mais estritamente ligados à dor e ao prazer" (MACH, 1902, p. 17).

$\mathrm{O}$ monismo neutral de Mach não salva portanto o Eu. De um ponto de vista metafísico, tal Eu perde-se na conexão impermanente dos elementos, e é necessário abandonar qualquer pretensão de lhe imputar uma existência autônoma (MACH, 1902, p. 18). Por outras palavras, uma vez assumido que o sujeito é feito de sensações, é impossível afirmar a integridade da "alegada unidade psíquica" e 
Gori, P.

portanto insistir na busca de um "lugar da alma" entre os cérebro, como no passado foi feito pela ciência ( $c f$. MACH, 1902, p. 20-21). Ainda que dirija uma crítica radical à pesquisa científica do seu tempo, Mach entende a necessidade de distinguir dois planos de discussão, salvaguardando o Eu enquanto noção de referência que não pode ser abandonada no âmbito meramente prático. "Apesar de tudo - admite conclusivamente Mach - para a minha concepção instintiva, o Eu é a coisa mais importante e persistente. É o que liga todas as minhas experiências e a fonte de todas as minhas actividades" (MACH, 1902, p. 273). Por outro lado, é inegável que no plano fisiológico persiste a ideia de uma concepção egoística e materialística da natureza, enquanto no plano teórico é impossível considerar Eu e corpos como noções substanciais. Se estas alegadas unidades demonstram de possuir uma mera utilidade prática, "nas pesquisas científicas mais avançadas somos obrigados a abandoná-las por serem insuficientes e inapropriadas" (MACH, 1902, p. 10). A consequência desse avanço é uma nova visão do mundo onde "desaparece o contraste entre o Eu e o mundo, entre sensação ou fenômeno e coisa e o que importa é somente a relação entre os elementos" (MACH, 1902, p. 10).

A referência à falácia da distinção entre aparência e realidade é o ponto de partida de uma seção de Conhecimento e erro (1905). Aqui Mach reassume a sua posição acerca do Eu, utilizando um tom fortemente nietzschiano. Escreve Mach:

A monstruosa, incognoscível «coisa em si» que fica debaixo dos fenômenos é, nitidamente, a irmã gêmea da coisa do pensamento comum, que perdeu os outros significados. Se (...) toda a essência do Eu foi etiquetado como aparência, o que nos pode continuar a interessar algo de incognoscível, exterior às fronteiras que o Eu nunca poderá ultrapassar? O que significa, senão um recair no pensamento comum, que, ao menos, sabe achar um núcleo sólido debaixo do "ilusório" fenômeno? (MACH, 1905, p. 10)"11

11 Para uma confirmação do carácter nietzschiano deste raciocínio e da linguagem de Mach, confrontese esta passagem com a parte final de Além do bem e do mal 17, onde Nietzsche afirma que a "rotina gramatical" faz do pensamento uma atividade e que cada actividade seja produzida por um agente,

22 | Cad. Nietzsche, Guarulhos/Porto Seguro, v.38, n.2, p. 13-35, maio/agosto, 2017. 
A caminho de uma filosofia sem alma. Uma abordagem psicofísica ...

A posição anti-metafísica de Mach é aqui bem ilustrada: ele rejeita completamente cada referência a uma coisa em si por se situar fora da nossa compreensão e uso. Trata-se de um conceito ilusório, e por isso inútil, enquanto todo o cognoscível se mantém dentro do horizonte do nosso Eu.

Na opinião de Mach, admitindo o princípio do paralelismo entre físico e psíquico, a questão da aparência e da realidade acaba por "perder o seu sentido", e é necessário considerar o Eu apenas como uma "relação funcional de elementos" (MACH, 1905, p. 11). Acerca deste ponto Mach é bastante claro: "Não precisamos de algo de ignoto, incognoscível posto por baixo da actividade do Eu". E continua: "Ora bem, debaixo do Eu existe algo quase inexplorado: o nosso corpo [unser Leib]. Todavia cada nova observação fisiológica favorece um melhor conhecimento do Eu" (MACH, 1905, p. 11). ${ }^{12}$ As conclusões de Mach traçam as direções que afastam os estudos psicológicos da visão metafísica tradicional. Na opinião de Mach, para se impor como ciência, a psicologia deve abandonar a demanda de um princípio permanente enquanto substrato da alma e qualquer tendência neste sentido é apenas uma regressão de uma posição que sustenta o carácter funcional das noções científicas. Assim - através de uma frase que faz lembrar as observações de Além do bem e do mal 54 e Genealogia da Moral I 13 - Mach observa que "quem ainda precisa ter um sujeito observante e agente no fundo, quando

e por consequência postula o Eu como causa do pensamento. Acrescenta Nietzsche: "Em virtude de um raciocínio semelhante e até igual, o atomismo antigo que unia a 'força atuante' à parte de matéria em que se encontra essa força, atua a partir desta: o átomo. Os espíritos mais rigorosos terminaram por desfazer-se deste último 'resíduo terrestre' e inclusive pode chegar o dia em que os lógicos prescindam desse pequeno 'algo' que ficará como resíduo ao evaporar-se o antigo e venerável 'eu"' (JGB/BM 17, KSA 5.31). Este confronto não visa sustentar uma influência directa entre os dois autores (neste caso, de Nietzsche a Mach), mas assinalar a conformidade dos seus raciocínios, justificada por uma contextualização das ideias desenvolvidas num substrato cultural comum.

12 Também acerca deste ponto, as semelhanças relativas às formas de pensar entre Mach e Nietzsche são múltiplas. Ambos, em particular, perspectivam a eliminação da distinção entre aparência e realidade ( $c f . G D / C I$, "Como o mundo verdadeiro se tornou finalmente fábula", KSA 6.80/81), e reintegram o Eu na dimensão corpórea (cf. Infra, n.15).

Cad. Nietzsche, Guarulhos/Porto Seguro, v.38, n.2, p. 13-35, maio/agosto, 2017. 
Gori, P.

a investigação [da dependência recíproca das representações] é concluída, não nota que podia ter poupado todo o trabalho da pesquisa, já que regressou de novo ao ponto de partida" (MACH, 1905, p. 11-12). Enfim, Mach refere-se explicitamente a estudos anteriores, citando o nome de Herbart e insiste no fato de que a psicologia, se quiser progredir, tem que abandonar qualquer referência metafísica, continuando, porém, a utilizar as noções tradicionalmente adotadas, cujo valor de subsídios práticos que permitem orientar o estudo não pode minimamente ser negado. Isto significa, segundo Mach, admitir a possibilidade de uma "psicologia sem alma" (MACH, 1905, p. 12).

\section{Lange e a psicologia científica}

Antes de Mach, dedicou-se à esse tipo de reflexões também o neokantiano Friedrich Lange, em dois capítulos acrescentados à segunda edição da História do materialismo (1875): Cérebro e alma e A psicologia científica. O primeiro capítulo abre-se com uma consideração a propósito da dificuldade de sustentar uma qualquer tese relativa à ligação entre cérebro e alma que não seja refutada pelos fatos. Lange, porem, não atribui a causa dessa dificuldade somente à esterilidade dos estudos da época. Afirma, aliás, que o problema maior seja teórico, consistindo no fato que ainda ninguém conseguiu formular uma hipótese não animista sobre a natureza da atividade do cérebro. Não tendo mais pontos de referência através dos quais desenvolver as suas investigações, Lange observa:

também os homens instruídos recaem sempre, como por desespero, nas teorias, há muito tempo refutadas pelos fatos, de uma localização da atividade do cérebro, segundo as diferentes funções da inteligência e do coração. Inúmeras vezes manifestamo-nos contra o preconceito que considera a simples conservação de concepções envelhecidas como um obstáculo para a ciência, tão grave como se costuma crer, mas a verdade é que o fantasma da alma, que aparece por entre as ruínas da escolástica, complica constantemente todo o problema. Dá para comprovar facilmente

24| Cad. Nietzsche, Guarulhos/Porto Seguro, v.38, n.2, p. 13-35, maio/agosto, 2017. 
A caminho de uma filosofia sem alma. Uma abordagem psicofísica ...

que esse fantasma (...) assume um papel significativo também entre aqueles que acham que se tinham libertado dele, isto é, de entre os principais apoiantes do materialismo; de fato, a concepção do cérebro que eles têm é inteiramente dominada pelas ideias triviais do passado sobre as faculdades imaginárias da alma (LANGE, 1875, p. 417-418).

A concepção escolástica, segundo a qual uma explicação dos fenômenos psíquicos é possível só a partir da determinação de um fundamento substancial dos mesmos, constitui o limite inacessível da psicologia. Também a visão materialista da natureza interpreta a alma como algo caracterizado por uma existência própria, um fantasma [Gespenst] que habita o cérebro. Lange critica esta visão das coisas, colhendo no afastamento da antiga metafísica o ponto de partida de onde a psicologia, que anseia identificar-se com a ciência natural, deveria avançar.

Em torno dessas considerações preliminares, Lange constrói o percurso de desenvolvimento da ciência psicológica e traça a direção que quer alcançar. Esse percurso passa, antes de mais, pelas pesquisas na área da frenologia, que, apesar de ser guiada pela vontade de ultrapassar "o ponto de vista do fantasma da alma" e centrada nas funções cerebrais, atribui um sujeito a cada uma dela e, mediante isto, "enche de fantasmas o crânio todo" (LANGE, 1875, p. 431). O raciocínio de Lange, portanto, toma em consideração a fisiologia, uma abordagem muito promissora e que, graças à obra de J. Müller, tinha constituído um efetivo avanço nas pesquisas psicológicas. Essa disciplina refere-se à dimensão corpórea para explicar os fenômenos psíquicos, sem ultrapassar o plano dos movimentos reflexos. Fica marcada, porém, por uma dificuldade de fundo, pois associar o psíquico ao físico revela-se impossível. $\mathrm{Na}$ opinião de Lange a impossibilidade de uma completa associação dos fenômenos psíquicos à dimensão corpórea deve-se ao fato desses fenômenos não existirem. Segundo ele, as noções utilizadas em psicologia não são outra coisa que o produto de uma classificação 
Gori, P.

puramente teórica, mas não determinam algo real em si mesmo. É portanto inútil procurar uma correspondência precisa com o corpo, porque o substrato fisiológico das faculdades da alma não está ligado às noções psicológicas de maneira unívoca. Por outras palavras: não existe uma verdadeira "sede" desta faculdade (LANGE, 1875, p. 443444). Apesar dessas dificuldades, Lange todavia concede à fisiologia um papel importante para o progresso da psicologia científica que constitui um passo à frente com respeito à concepção materialista, fechada na sua convicção de circunscrever o fundamento físico das "faculdades da alma" (LANGE, 1875, p. 454).

É então preciso olhar para a fisiologia a fim de fazer progredir os estudos sobre o cérebro, mas a condição prévia é evitar qualquer referência a causas mitológicas para explicar as funções psíquicas ( $c f$. LANGE, 1875, p. 460-463). Esse afastamento representa a passagem decisiva para uma psicologia que não quer ser mais metafísica, e é portanto o elemento sobre o qual Lange insiste quando perspectiva a efetiva possibilidade de fundar uma psicologia científica. Um passo em frente nessa direcção tinha sido feito por Herbart, a quem Lange reconhece o mérito de ter conseguido estruturar uma nova modalidade da investigação sobre a psique (LANGE, 1875, p. 473). Essa direção de pesquisa, porém, fracassa pela referência a um conceito de alma absolutamente simples, que só faz sentido se não for minimamente circunscrito. Pelo contrário, observa Lange "no pequeno número de fenômenos tornados acessíveis para uma observação mais precisa, não se encontra o motivo para admitir uma alma, seja qual for o sentido, mais ou menos rigoroso que se atribui a esta palavra" (LANGE, 1875, p. 474). Daí a conclusão segundo a qual o verdadeiro progresso da psicologia deveria consistir na recusa de qualquer hipótese acessória e não necessária, que na época de Lange era ainda admitida. Escreve Lange:

$26 \mid$ Cad. Nietzsche, Guarulhos/Porto Seguro, v.38, n.2, p. 13-35, maio/agosto, 2017. 
A caminho de uma filosofia sem alma. Uma abordagem psicofísica ...

"Mas a palavra psicologia não significa teoria da alma? Como podemos, portanto, imaginar uma ciência de que não se pode dizer se tem ou não um objeto?" Eis aqui um lindo exemplo da confusão em nome da coisa! Temos um nome tradicional para um grupo considerável mas vagamente delimitado. Esse nome vem de uma época em que ainda não se conheciam as exigências atuais de uma ciência rigorosa. Deveríamos recusá-lo porque mudou o objeto da ciência? Isto seria um pedantismo pouco prático. Admitimos assim, serenamente, uma psicologia sem alma. $\mathrm{O}$ nome pode continuar a servir, até quando existirá algo por fazer que uma outra ciência não se disponibilize a fazer come deve ser. (LANGE, 1875, p. 474)

A posição de Lange, no que toca a esse ponto, é particularmente importante para compreender as seguintes considerações de Nietzsche acerca do problema do sujeito. Os dois autores partilhavam, de fato, a mesma convicção: o progresso dos estudos mostra a irrealidade de uma série de hipóteses substancialistas que, por isso, devem ser abandonadas. Ao mesmo tempo, todavia, Lange observa que nem tudo o que há é para rejeitar. No caso específico da psicologia, uma vez que se reconfigure o objecto da investigação (a alma) em termos não metafísicos, esse objeto pode continuar a ser preservado como ponto de referência da pesquisa.

\section{Filosofia sem "eu"}

As considerações formuladas até qui delineiam o contexto da posição de Nietzsche no que respeita ao problema do Eu na filosofia. Para além disso, a referência às ideias de Lange e Mach é particularmente útil para compreender alguns aspectos da crítica de Nietzsche ao "eu penso", sendo que ele tinha um conhecimento direto das obras de ambos os autores. ${ }^{13}$

13 Se no caso de Lange a dívida é facilmente demonstrável, a mesma coisa não se pode dizer quanto a Mach, pois não é citado em nenhuma obra de Nietzsche e não é possível associar a ele nenhuma passagem publicada ou inédita. Não obstante isso, pode-se reparar numa profunda conformidade acerca de algumas posições epistemológicas, sinal, com toda probabilidade, de um substrato de referência comum. Para uma reflexão sobre a relação entre Nietzsche e Mach, desenvolvida a partir da leitura que Nietzsche fez de das Analises das sensações, veja-se Gori (2019) e (2012).

Cad. Nietzsche, Guarulhos/Porto Seguro, v.38, n.2, p. 13-35, maio/agosto, 2017. 
Gori, P.

Em termos gerais, Nietzsche partilha, com os autores que ao longo do século XIX afirmaram a possibilidade de fundar uma psicologia científica, a ideia de que é necessário afastar-se de um sistema de pensamento que regista entidades substanciais em toda a parte, como se fosse possível atingir o conhecimento de um evento específico só por meio delas. Pelo contrário, na opinião de Nietzsche, a filosofia precisa de ultrapassar a velha metafísica e dar menos importância àqueles pontos de referência tão úteis como ilusórios. O eu é precisamente um destes entes que não é possível definir senão a partir da atividade psíquica que se julga sua descendente. De acordo com as observações de Lange e Mach, que lamentavam a inutilidade de uma pesquisa centrada na individuação de uma "sede da alma" e perspectivavam uma psicologia capaz de reconhecer a inconsistência ontológica do seu objeto de investigação, Nietzsche critica, na filosofia do seu tempo, a tendência para procurar um sujeito entendido como causa dos pensamentos. No seu entender, esse sujeito perde-se nos meandros dos processos fisiológicos que se encontram numa dimensão inferior, acabando por se identificar com eles. ${ }^{14}$

O ponto de vista de Nietzsche sobre a questão do sujeito é compatível com a orientação crítica com que Mach enfrenta o problema do saber metafísico. Nietzsche interessa-se, de fato, pelo caráter meramente fictício do eu, que, no seu intender, é o produto de uma atividade secundária do pensamento - a da lógica - que intervém

14 A questão relativa à redução dos estados mentais a estados corpóreos em Nietzsche (cf. Nachlass/ FP 1883, 9 [41], KSA 10.358) mereceria um discurso à parte, tendo em conta antes de mais que ele nunca fornece uma definição clara do que entende com o termo corpo [Leib]. A esse respeito, as observações de Luca Lupo oferecem um importante auxílio: "As noções de corpo que [Nietzsche] pensa é problemática, não unívoca, não relacionável com uma forma de materialismo positivista nem com uma forma de vitalismo: em alternativa à palavra 'corpo', o filosofo utiliza a locução mais cauta 'o que chamamos de corpo' e acerca desse termo diz que é um 'símbolo', para indicar uma específica atividade, isto é, a cooperação de uma multiplicidade de seres. Nietzsche pensa numa noção de corpo como um campo de forças, entidade organizada plural e múltipla, em definitiva: sistema de relações" (LUPO, 2006, p. 133). Veja-se acerca disso também Gerhard (2006).

28 | Cad. Nietzsche, Guarulhos/Porto Seguro, v.38, n.2, p. 13-35, maio/agosto, 2017. 
A caminho de uma filosofia sem alma. Uma abordagem psicofísica ...

na atribuição de um sujeito a um processo que é essencialmente desprovido desse elemento, para finalidades exclusivamente práticas:

O que me separa mais profundamente dos metafísicos é isto: não lhes concedo que o "Eu" seja a essência que pensa; pelo contrário, considero o Eu uma construção do pensamento, que tem o mesmo valor de "matéria", "substância", "individuo", "escopo", "número"; isto é, apenas uma ficção reguladora, graças à qual esboçamos, inventamos, num mundo em devir, uma espécie de estabilidade e, por conseguinte, de "cognoscibilidade". (...) O pensamento é que determina o "Eu", mas acreditou-se até agora, como acredita o "povo", que no "eu penso" estivesse presente algo de imediatamente certo e que esse "eu" fosse a causa do pensamento (Nachlass/ FP 1885, 35[35], KSA 11.526)

Conforme se lê neste apontamento, Nietzsche parece incluir o eu entre os elementos substanciais surgidos a partir da tentativa de traduzir o mundo externo numa linguagem que podia ser compreendida e utilizada pelo nosso intelecto. É esta a ideia fundamenta de Mach que, como vimos, considera Eu e corpo como noções que satisfazem exigências puramente práticas, por baixo das quais não é possível detectar nenhuma entidade dotada de autonomia e permanência absoluta. Nietzsche ainda concorda implicitamente com Mach ao admitir que a determinação de uma entidade individual capaz de juntar as multiplicidades de percepções, afetos e sentimentos que associamos ao nosso corpo, procede de uma operação puramente intelectiva. ${ }^{15}$ Trata-se, ainda por cima, de uma tendência a admitir um ser numa realidade caracterizada pela mudança, e portanto manifesta os caracteres de uma perspectiva de pensamento puramente metafísica, segundo as observações de Lange.

Tendo em conta outras considerações de Nietzsche presentes nos seus cadernos ( $c f$. em particular Nachlass/FP 1884, 26[92];

15 No FP 1887-1888, 9 [89], KSA 12.382, Nietzsche assinala de modo mais explícito a dependência da noção de Eu que a lógica tem. Isto circunscreve um nucleo de permanência onde referir as sensações e as modificações, inseríveis na esfera do sentido interno.

Cad. Nietzsche, Guarulhos/Porto Seguro, v.38, n.2, p. 13-35, maio/agosto, 2017. 
Gori, P.

1885, 38[1]; 1886-87, 11[113]), que induzem a pensar que ele admitia uma naturalização dos processos do pensamento, da qual seguiria uma concepção epifenoménica da consciência, podemos deduzir que o aspecto que distingue o Eu das outras entidades substanciais é a função de "causa" dos sentimentos, percepções e recordações unificados nele. ${ }^{16}$ A entidade espiritual é circunscrita a partir da sua capacidade de ativar os atos psíquicos, com a ilusória convicção de poder encontrar o ponto de emanação deles, quando, na realidade, só é possível detectar os efeitos desses actos. Para Nietzsche, o sujeito não é outra coisa senão uma criação da atividade representativa, originada com o intuito de poder "indicar a força que age, inventa, pensa, por isso distinta da cada agir, inventar, pensar singularizado" (Nachlass/FP 1885, 2 [152], KSA 12.141). ${ }^{17}$ $\mathrm{Na}$ visão de Nietzsche, o pensamento não é separável da atividade fisiológica que o determina; por conseguinte, não há nenhum dualismo sujeito-objeto que o substancialize. Não existe algum autor dos pensamentos; os pensamentos desenvolvem-se necessariamente a partir do processo interno do organismo. Pela mesma razão, não há nenhum sujeito distinto das sensações criadas pela nossa faculdade perceptiva; essas sensações manifestam-se de maneira espontânea e só sucessivamente são registadas a um nível consciente, e assim organizadas e "compreendidas". É só a partir deste ponto que intervém

16 Para um estudo mais aprofundado da questão do pensamento e da consciência, aconselho a leitura de Lupo (2006), Emden (2005) e Abel (2001). A discussão sobre o carácter epifenomênico da consciência encontra-se em Leiter (2002) e Katsafanas (2005).

17 Veja-se também Nachlass/FP 1886, 7[1], KSA 12.247 e, sobretudo, GM/GM I 13, KSA 5.278 onde Nietzsche observa que "não existe 'ser' por trás do fazer, do atuar, do devir; 'o agente' é uma ficção acrescentada à ação - a ação é tudo". A vontade de encontrar um sujeito agente secundário ao desenvolvimento dos eventos é um tema em torno do qual Nietzsche insistiu bastante, lamentando, em particular, a tendência do homem a antropomorfizar a dinâmica natural. Todo isto mostra-se evidente no caso da interpretação da ligação de causa e efeito, modelo de uma dinâmica puramente necessária que todavia é habitualmente descrita segundo os termos de um agir humano intencional. A tendência de fundo é projetar nas coisas o modelo de atividade que se tornou habitual, atribuindo às forças que movem a realidade material os caracteres do sujeito (cf. Nachlass/FP 1885, 2 [83], KSA 12.101 e 1888, 14 [95], KSA 13.237). Esse detalhe foi realçado também por Lange na História do Materialismo (1875, p. 264).

30 | Cad. Nietzsche, Guarulhos/Porto Seguro, v.38, n.2, p. 13-35, maio/agosto, 2017. 
A caminho de uma filosofia sem alma. Uma abordagem psicofísica ...

a "ficção reguladora" que outra coisa não é senão um subsídio lógico para categorizar as sensações, cuja utilidade é tão indubitável como a sua inconsistência ontológica.

Estas considerações levam-nos ao ponto inicial do nosso discurso, isto é, aos motivos da crítica que Nietzsche dirige ao "eu penso" em JGB, quando escreve que "é uma falsificação dos estados dos fatos dizer: o sujeito "eu' é a condição do predicado "penso" (JBG/BM 17, KSA 5.30/31). A "certeza imediata" cartesiana deveria ser substituída pela ideia de que os processos cognitivos ocorram sem a presença de um sujeito externo que os determine, isto é, que seja "algo" e não "eu", a pensar (JBG/BM 17, KSA 5.30/31). ${ }^{18}$ Esta passagem constituiria um progresso notável em âmbito filosófico, já que implicaria, finalmente, um afastamento daquela "necessidade metafísica" que tanto domina no âmbito científico como no religioso e que obriga a trazer de volta para a realidade os fundamentos materiais (os átomos) e espirituais (as almas) absolutos.

Chegados a esse ponto, é possível dar uma resposta à questão colocada inicialmente, ou seja, em que termos Nietzsche pensa numa "filosofia sem o Eu". A partir do momento em que se concebe o Eu como um resíduo da metafísica da substância, esta possibilidade não parece tão paradoxal. A filosofia pode, efetivamente, prescindir dessa noção substancial - e deve fazê-lo, se quiser ser verdadeiramente "anticristã" (JGB/BM 54, KSA 5.73). Mas isto não deixa de ser uma tarefa circunscrita a um âmbito epistémico muito específico, e portanto a uma forma particular de Eu, não comportando o abandono desta ideia enquanto primeira referência da autodeterminação do sujeito agente. Por outras palavras, a resposta à pergunta "se desaparecer o $\mathrm{Eu}$ da psicologia e da filosofia (a causa do pensamento), também a alma (o princípio da concepção prática do si) desaparece?" é negativa. Não obstante a sua radicalidade, a crítica nietzscheana do Eu não tira ao homem a referência da sua subjetividade, posto que essa referência

18 Para um estudo mais aprofundado de Além do bem e do mal, 17, veja-se Loukidelis (2013).

Cad. Nietzsche, Guarulhos/Porto Seguro, v.38, n.2, p. 13-35, maio/agosto, 2017. 
Gori, P.

seja concebida de forma diferente: despojada da casca metafísica que a recobre. Tudo isto é o que podemos deduzir, por exemplo, de JBG/BM 12, onde Nietzsche contesta a "necessidade metafísica" que no seu tempo continua a marcar a descrição do mundo, e convida a rejeitar tanto os princípios do atomismo materialista como "o outro e mais funesto atomismo que o cristianismo ensinou-nos tão bem e durante tanto tempo, o atomismo das almas», isto é «a crença que considera alma como algo indestrutível, de eterno, de indivisível" (JGB/BM 12, KSA 5.26). Nietzsche observa que "não é necessário livrar-nos também da 'alma' e renunciar a uma das mais antigas e venerandas hipóteses (...). A estrada para novas formas e para novos refinamentos da hipótese da alma fica em aberto: e os conceitos como 'alma mortal' e 'alma como pluralidade do sujeito' e 'alma como estrutura social dos instintos e das paixões' querem ter, a partir de agora, direito de cidadania na ciência" (JGB/BM 12, KSA 5.26).

$O$ raciocínio de Nietzsche corresponde, em muitos aspectos, ao raciocínio de Lange, e insiste em particular sobre a necessidade de uma reformulação da noção de alma, de modo que ela possa continuar a ser adotada como ponto de referência do sujeito. Demonstrar que a alma e o Eu são conceitos desprovidos de uma consistência ontológica, e que a rejeição deles seja necessária no âmbito filosófico, não implica que eles percam completamente o valor no âmbito prático. Assim, uma vez retirado à alma o seu estatuto de "mônada, de atomon", o passo seguinte não consiste na sua completa dissolução, mas na sua reconfiguração em termos mediatos, na sua relativização (segundo o exemplo de Nietzsche, a alma torna-se "mortal", perde o seu carácter substancialístico, revelando-se "pluralidade do sujeito", ou é relegada para uma dimensão pulsional onde Nietzsche coloca também o Eu).

A última questão por resolver diz respeito à utilidade que, no parecer de Nietzsche, pode ter o progresso do pensamento filosófico em direção a uma renúncia do Eu como entidade substancial. A resposta envolve a perspectiva geral do Nietzsche mais tardio, o 
A caminho de uma filosofia sem alma. Uma abordagem psicofísica ...

qual se dedica a uma crítica do conceito de verdade das noções assumidas pelo homem para orientar o seu agir. Nietzsche não pretende rejeitar os princípios da auto-representação do homem, que afinal são as referências do seu agir prático. Ao invés, Nietzsche tenta "transvalorar" esses princípios, despojando-os do significado que lhes tinha sido atribuído até agora, ao fim de possibilitar a determinação de uma nova humanidade que represente um novo estádio da existência. Admitir a possibilidade de uma "filosofia sem Eu" significa, enfim, reconhecer que por trás dessa noção há apenas uma particular modalidade de interpretação do mundo, cuja reconfiguração permitirá ao homem referir-se a si próprio e à realidade que o rodeia através uma maneira nova (transvalorada).

\section{Referências bibliográficas}

ABEL, G. Bewußtsein - Sprache - Natur. Nietzsches Philosophie des Geistes. In: Nietzsche-Studien, n. 30, 2001, p. 1-43.

BANKS, E.C. Ernst Mach's World Elements. A Study in Natural Philosophy, Dodrecht: Kluwer, 2003.

BORNEDAL, P. The Surface and the Abyss. Berlin: de Gruyter, 2010.

EMDEN, C.J. Nietzsche on Language, Consciousness and the Body. Chicago: University of Illinois Press, 2005.

FECHNER, G. Elemente der Psychophysik. Leipzig: Breitkopf und Hartel, 1860.

GERHARD, V. The Body, the Self, and the Ego. In: A Companion to Nietzsche, ed. K. ANSELL-PEARSON, Oxford: Blackwell, 2006, p. 273-296.

GORI, P. Il meccanicismo metafisico. Scienza, filosofia e storia in Nietzsche e Mach. Bologna: Il Mulino, 2009.

GORI, P. Nietzsche as Phenomenalist? In: Nietzsches Wissenschaftsphilosophie. ed. H. HEIT, G. ABEL e M. BRUSOTTI, Berlin: de Gruyter , 2012, p. 345-356.

Cad. Nietzsche, Guarulhos/Porto Seguro, v.38, n.2, p. 13-35, maio/agosto, 2017. 
Gori, P.

GUZZARDI, L. Lo sguardo muto delle cose. Milano: Raffaello Cortina, 2010.

HEIDELBERGER, M. Die innere Seite der Natur: Gustav Theodor Fechners wissenschaftlich-philosophische Weltauffassung. Frankfurt a.M.: Klosterman, 1996.

KANT, I. Kritik der Reinen Vernunft. 1. und 2. Auflage. In: Immanuel Kants Werkausgabe, Band III e IV, Berlin: Suhrkapm, 1974.

KATSAFANAS, P. Nietzsche's Theory of Mind. Consciousness and Conceptualization. In: European Journal of Philosophy, n. 13, 2005, p. 1-31.

LANGE, F.A. Geschichte des Materialismus. Bd. 2. Leipzig: Reclam, 1875.

LEARY, D.E. The historical foundations of Herbart's mathematization of Psychology. In: Journal of the History of Behavioral Sciences, n. 16, 1980, p. 150-163.

LEHMANN, G. Kant im Spätidealismus und die Anfänge der neukantische Bewegung. In: Materialen zur Neukantismus-Diskussion, hg. H.L. OLLIG, Darmstadt: Wissenschaftliche Buchgesellschaft, 1987, p. 44-65.

LEITER, B. Nietzsche on Morality. London: Routledge, 2002.

LOUKIDLIS, N. Es denkt. Ein Kommentar zum Aphorismus 17 von «Jenseits von Gut und Böse». Würzburg: Königshausen \& Neumann, 2013.

LOUKIDELIS, N. Quellen von Nietzsches Verständnis und Kritik des cartesischen cogito, ergo sum. In: Nietzsche-Studien, n. 34, 2005, p. 300-309.

LUPO, L. Le colombe dello scettico. Pisa: ETS, 2006.

MACH, E. Erkenntnis und Irrtum. Leipzig: Barth, 1905.

MACH, E. Analyse der Empfindungen. Jena: Fischer, 1902.

MARTINELLI, R. Misurare l'anima. Filosofia e psicofisica da Kant a Carnap. Macerata: Quodlibet, 1999.

PIPPIN, R. Nietzsche, Psychology, and First Philosophy. Chicago: Chicago University Press, 2010.

POGGI, S. I sistemi dell'esperienza. Bologna: Il Mulino, 1977.

34 Cad. Nietzsche, Guarulhos/Porto Seguro, v.38, n.2, p. 13-35, maio/agosto, 2017. 
A caminho de uma filosofia sem alma. Uma abordagem psicofísica ...

SACHS-HOMBACH, K. Der Geist als Maschine. Herbarts Grundlegung der naturwissenschaftlichen Psychologie. In: Das sichtbare Denken, hg. J.F. MAAS, Amsterdam: Rodopi, 1993, p. 91-111.

SALAQUARDA, J. Nietzsche und Lange. In: Nietzsche-Studien, n. 7, 1978, p. 236-253.

STACK, G. Lange and Nietzsche. Berlin: de Gruyter, 1983.

\begin{abstract}
Friedrich Nietzsche's criticism towards the substanceconcept "I" plays an important role in his thought, and can be properly understood by making reference to the 19th century debate on the scientific psychology. Friedrich Lange and Ernst Mach gave an important contribution to that debate. Both of them thought about a "psychology without soul", that is, an investigation that gives up with the old metaphysics of substance in dealing with the mind-body problem. In this paper I shall deal with Lange's and Mach's views, in order to shed some light on Nietzsche's rejection of the I in philosophy.
\end{abstract}

Keywords: Psychology - Psychophysics - Lange - Mach.

Artigo recebido para publicação em 18/02/2017. Artigo aceito para publicação em 18/06/2017. 